\title{
Anomalies of Left Coronary Artery Origin Affecting Surgical Repair of Hypoplastic Left Heart Syndrome and Shone Complex
}

\author{
Tania Saroli, M.D., ${ }^{*}$ Sarah Gelehrter, M.D., ${ }^{*}$ Carlen A. Gomez-Fifer, M.D., ${ }^{*}$ \\ Mary E. van der Velde, M.D., ${ }^{*}$ Edward L. Bove, M.D., $†$ and Gregory J. Ensing, M.D.* \\ *Division of Pediatric Cardiology, Department of Pediatrics and Communicable Diseases, \\ University of Michigan, Ann Arbor, Michigan, and †Section of Cardiac Surgery, Department of \\ Surgery, University of Michigan, Ann Arbor, Michigan
}

There has traditionally been less concern regarding coronary anomalies with left-sided congenital heart lesions such as hypoplastic left heart syndrome (HLHS) or Shone complex than with other lesions. However, coronary anomalies in this setting can profoundly affect surgical intervention, particularly when surgical repair involves the ascending aorta. We describe four patients with congenital left-sided heart lesions in which left coronary artery (LCA) anomalies substantially affected intervention and outcome. In the first two cases, the coronary anomalies were not identified prospectively and resulted in surgical injury directly to the coronary or to its surrounding region. In the latter two cases, successful identification of the coronary anomaly preoperatively allowed for modification of surgical technique and / or intervention. We conclude that detailed coronary artery assessment should be part of the routine echocardiographic evaluation of congenital left-sided heart lesions that require surgery. (ECHOCARDIOGRAPHY, Volume 25, August 2008)

\section{Coronary artery anomalies, Hypoplastic Left Heart Syndrome, Shone complex}

Coronary artery anomalies have been well described in association with complex congenital cardiac lesions such as pulmonary atresia with intact ventricular septum, D-transposition of the great arteries (D-TGA), and tetralogy of Fallot, where their course may substantially affect surgical intervention. Traditionally, there has been less concern regarding coronary anomalies with left-sided heart lesions such as hypoplastic left heart syndrome (HLHS) or Shone complex. However, coronary anomalies in this setting could profoundly affect surgical intervention, particularly when surgical repair involves the ascending aorta. We describe four patients with left heart lesions and left coronary artery (LCA) anomalies, some identified prospectively and others not, which substantially affected intervention and outcome.

Address for correspondence and reprint requests: Tania Saroli, M.D., University of Michigan Health System, L1242 Women's, Box 0204, 1500 East Medical Center Drive, Ann Arbor, Michigan 48109-0204. Fax: 734-936-9470; E-mail: tsaroli@umich.edu

\section{Cases}

Case 1

A 2-day-old male with HLHS-variant anatomy underwent Norwood palliation. Preoperative echocardiogram on the day of birth demonstrated mitral atresia with a hypoplastic left ventricle, aortic hypoplasia, and ventricular septal defect (VSD). Coronary arteries were not examined in detail, but were thought to arise normally based upon parasternal short-axis images. When the ascending aorta was opened during the course of the Norwood procedure, the left main coronary artery was inadvertently transected due to a long intramural course. Repair was complicated by the extremely small caliber of the vessel. After failure to wean successfully from cardiopulmonary bypass, the patient was placed on extracorporeal membrane oxygenation (ECMO). He later succumbed to multiorgan system failure. Retrospective review of the initial echocardiogram demonstrated a superiorly positioned origin of the LCA from the ascending aorta. 


\section{Case 2}

A newborn girl with HLHS presented for Norwood palliation. Preoperative echocardiogram showed typical anatomy, with mitral and aortic hypoplasia and a moderately hypoplastic left ventricle. Coronary arteries appeared to arise normally. Intraoperatively, an incision was made in the ascending aorta approximately $8 \mathrm{~mm}$ superior to the level of the right coronary artery (RCA). The incision was noted to be immediately adjacent to the orifice of the LCA. Attempted weaning from cardiopulmonary bypass was unsuccessful due to poor ventricular contractility, necessitating exploration of the coronary artery. Inspection of the LCA demonstrated the vessel to be patent but kinked. A patch of homograft material was used to augment the proximal portion of the LCA. The patient was successfully weaned from cardiopulmonary bypass, but subsequently required ECMO within in the first few postoperative hours due to low cardiac output. She was decannulated after 6 days. Retrospective review of the preoperative echocardiogram revealed a superior origin of the LCA.

\section{Case 3}

After a prenatal diagnosis of HLHS, a newborn male was diagnosed with Shone complex. Echocardiogram demonstrated a mildly hypoplastic mitral valve with a single papillary muscle, a small, but apex-forming, left ventricle, a mildly hypoplastic bicuspid aortic valve, diffuse aortic arch hypoplasia, and atrial and ventricular septal defects. The RCA origin appeared to be normally positioned; the left originated more superiorly, approximately $5 \mathrm{~mm}$ above the aortic annulus. During complete repair of the cardiac anomalies, the techniques of aortic cannulation and arch augmentation were altered to avoid injury to the LCA. Postoperative course was uncomplicated.

\section{Case 4}

A 2-day-old newborn male presented for intervention for Shone complex. Echocardiogram demonstrated mild mitral hypoplasia, VSD, mild aortic valve dysplasia, mildly hypoplastic aortic arch with periductal coarctation, and diminished left ventricular function. Coronary arteries were not dilated. However, echocardiographic images demonstrated the LCA origin from the undersurface of the right pulmonary artery (RPA) (Fig. 1). The patient underwent complete operative repair including reimplantation of the LCA to the aorta. Discharge echocardiogram demonstrated normal biventricular systolic function with normal antegrade flow direction and velocity in the LCA.

\section{Discussion}

Congenital coronary artery anomalies have been poorly described in association with complex left-sided lesions such as HLHS or Shone complex. The exact incidence of the association of these lesions with anomalous coronary arteries is unknown. The majority of reports involves case series or single case studies. ${ }^{1-16}$ The most common coronary anomalies associated with left-sided lesions consist of ventriculocoronary fistulas or coronary tortuosity; ${ }^{14}$ anomalies of coronary origin are less common.

Our first three cases involve a superior origin of the LCA from the aorta, with or without

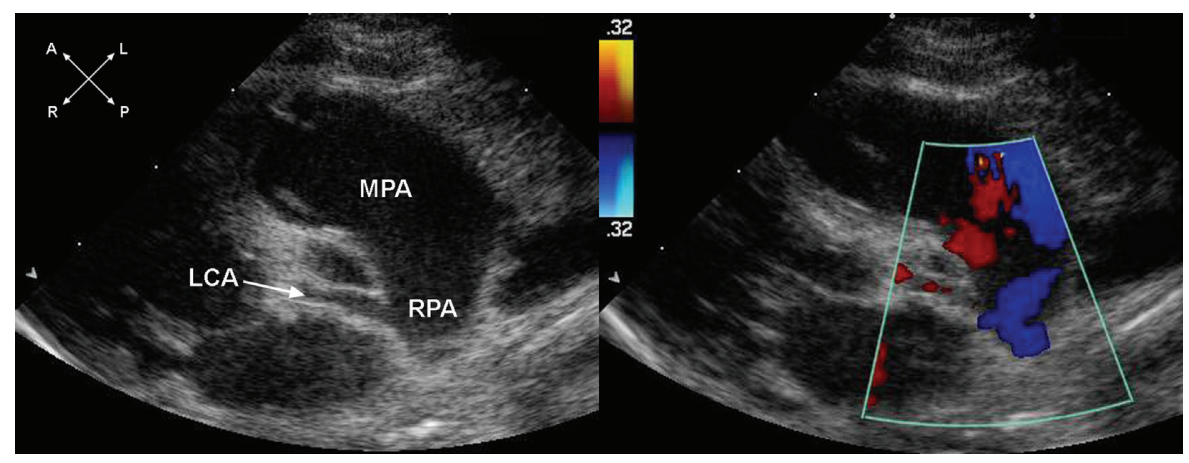

Figure 1. Oblique parasternal short-axis view in $2 D$ and with color, showing a normal size left coronary artery (LCA) arising from the right pulmonary artery (RPA) near its takeoff from the main pulmonary artery $(M P A) . A=$ anterior; $L=$ left; $P=$ posterior; $R=$ right. 
Figure 2. A. Parasternal short-axis view showing the right (RCA) and left coronary arteries (LCA) appearing to arise normally from the aortic root (Ao). $A=$ Anterior $;=$ Left $; P=$ Posterior; $R=$ Right. B. Subcostal coronal image demonstrating a superior origin of the left coronary artery (LCA) from the ascending aorta compared to the level of the aortic valve $(A V)$. $I=$ inferior; $L=$ left; $L V=$ left ventricle; $R=$ right; $S=$ superior.

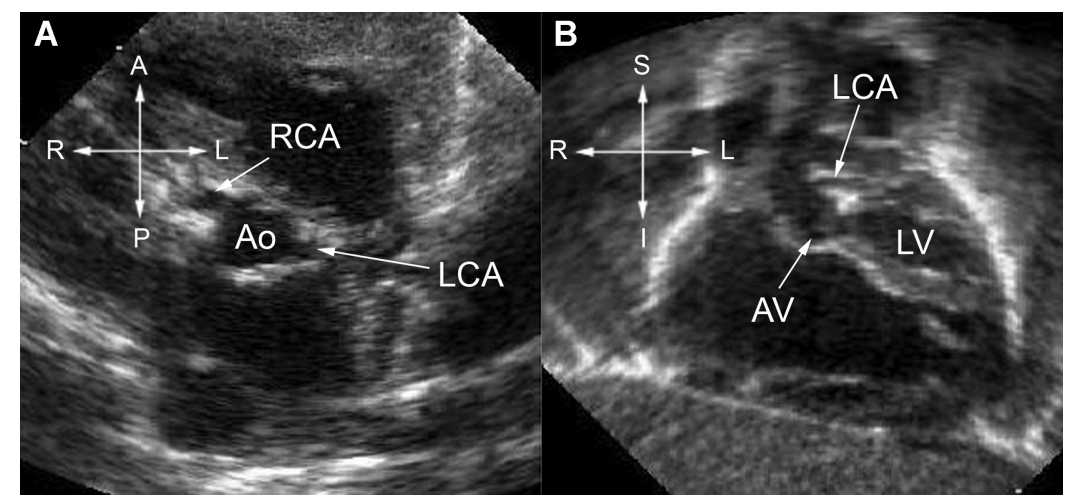

intramural course. Superior origins in Cases 1 and 2 were not identified prospectively and resulted in surgical injury directly to the coronary or to its surrounding region. In Case 3 , successful identification of the superior origin of the coronary preoperatively allowed for modification of surgical technique.

The parasternal short-axis echocardiographic view is standard at many institutions for assessing coronary artery origins from the aortic sinuses. The patients in our series had relatively normal appearing short-axis views, revealing the limitations of using this view alone to rule out coronary artery anomalies. Retrospective review of their complete echocardiographic studies, which included images of the ascending aorta from the parasternal longaxis and subcostal coronal views, did in fact demonstrate the abnormal superior position of the origin of the LCA (Fig. 2). Parasternal long-axis as well as subcostal imaging is often helpful in determining superior coronary origins. Another misleading aspect of the parasternal short-axis view when assessing coronary arteries involves the possibility of not detecting an intramural coronary course, as there can often be false dropout of the wall between the intramural coronary artery and the aortic root. Color flow mapping can assist in some cases to diagnose false dropout masquerading as the coronary origin.

There is no uniform consensus in the medical literature regarding definition of a "high takeoff" of coronary arteries from the aorta, let alone the definition of the level of "normal" coronary artery origins. In pathologic reviews, anywhere from $56 \%$ to $78 \%$ of normal hearts have coronary origins located at or below the sinotubular junction. ${ }^{17,18}$ Review of the medical literature reveals varied classifications of "high takeoff," such as an orifice arising $1 \mathrm{~cm}$ or more above the aortic cusp margin, ${ }^{19,20} 1 \mathrm{~cm}$ or more cephalad to the sinotubular junction, ${ }^{21,22}$ more than $0.5 \mathrm{~cm}$ above the sinotubular junction, ${ }^{23}$ or a relative measurement of $120 \%$ or more of the depth of the aortic sinus, or $20 \%$ above the sinotubular junction. ${ }^{18}$

High takeoff of a coronary artery from the wall of the aorta is historically considered a normal variant. A recent publication by Lytrivi, et al. presents the largest series to date of cases of clinically "silent" congenital coronary anomalies; 59 of 168 patients had "high coronary takeoff," and all were either asymptomatic or undergoing evaluation for unrelated cardiac malformations. ${ }^{24}$ However, there are case reports of sudden death in patients with high takeoff of a coronary artery ${ }^{25,26}$ with no significant coronary atherosclerosis. The majority of cases demonstrated a funnel-shaped ostium on pathologic review, some with intramural course of the initial portion of the coronary. Mahowald, et al. propose that the mechanism of sudden death could involve an acute angle at which the ectopic coronary artery leaves the aorta, resulting in a flap-like mechanism at the coronary ostium, which then could become obstructed with expansion of the aorta during exercise. ${ }^{23}$

A superior, or high, origin of a coronary artery is also rarely described with left heart lesions. There are case reports of abnormally high origins of the RCA in normal hearts, associated with atrial septal defect, with VSD with patent ductus arteriosus, and with bicuspid aortic valve. ${ }^{27-32} \mathrm{~A}$ series of patients with truncus arteriosus reported that high takeoff occurred in $19 \%$ of the LCA, and $9 \%$ of the RCA; ${ }^{33}$ high takeoff is a frequent finding in D-TGA. ${ }^{33}$ Other abnormal coronary origin positions that have been described include a high origin of both coronary arteries from the left aortic wall in a normal heart, ${ }^{34}$ and origin of a coronary 
artery from the descending thoracic aorta in an infant with HLHS. ${ }^{15}$ In the case series described above from Lytrivi et al. outlining clinically "silent" congenital coronary anomalies, none of the cases of "high coronary takeoff" was described in association with HLHS or Shone complex. ${ }^{24}$

Case 4 involved successful preoperative detection of the LCA arising from the RPA in a patient with Shone complex. Anomalous coronary artery from the pulmonary artery can cause ventricular dysfunction after the fall of pulmonary vascular resistance. As diastolic pulmonary artery pressures decrease after birth, flow reverses in the coronary from the left ventricular myocardial bed into the pulmonary artery, causing myocardial ischemia or infarction. Perfusion of the left coronary bed is retrograde and supplied by collateral circulation from the RCA, which arises from the higherpressure aorta. ${ }^{35}$ Echocardiography is diagnostic in most patients, but in newborns, the usual signs such as a dilated RCA, left ventricular dysfunction with endocardial brightness, and abnormal flow direction in the LCA will not be present. As well, anomalous origin of a coronary artery from the pulmonary artery should be excluded in newborns with a patent ductus arteriosus who are being considered for medical treatment or surgical ligation. In these cases, the reduction in pulmonary arterial pressure following ligation of a large patent ductus may contribute to coronary steal. In our case, the coronary artery anomaly was clearly defined prospectively and allowed modification of surgical intervention to include coronary reimplantation, with an excellent result. There are few published case reports describing an abnormal origin of the left main ${ }^{1-3}$ or circumflex ${ }^{4,16}$ coronary artery from the RPA in patients with HLHS. There are additional case reports of anomalies such as the $\mathrm{RCA}^{5}$ or a single coronary artery ${ }^{6}$ arising from the pulmonary artery in HLHS. To our knowledge, this is the first reported case of the LCA arising from the RPA in Shone complex.

\section{Conclusion}

Detailed coronary artery assessment, including careful evaluation of coronary artery origins, their relationship to the aortic annulus, and the coronary artery course, should be part of the routine echocardiographic assessment of left-sided heart lesions, in addition to those lesions more classically known to be associ- ated with coronary anomalies. Identification of coronary artery anomalies is particularly important for surgical repairs involving the ascending aorta. Coronary artery origins should be examined from multiple echocardiographic views rather than relying only on parasternal short-axis views, which can prove deceiving.

\section{References}

1. Malec E, Mroczek T, Pajak J, et al: Hypoplastic left heart syndrome with an anomalous origin of the left coronary artery. Ann Thorac Surg 2001;72:2129 2130.

2. Sarris GE, Drummond-Webb JJ, Ebeid MR, et al: Anomalous origin of left coronary from right pulmonary artery in hypoplastic left heart syndrome. Ann Thorac Surg 1997;64:836-838.

3. Nosal M, Omeje IC, Poruban R: Hypoplastic left heart syndrome with anomalous origin of left coronary artery from the right pulmonary artery: Successful surgical treatment in a neonate. Eur J Cardiothorac Surg 2005;28:497-498.

4. Villa E, Brancaccio G, Carotti A, et al: Circumflex coronary artery from right pulmonary artery in hypoplastic left heart syndrome. Ann Thorac Surg 2005;80:1919-1920.

5. Cleuziou J, Haas F, Schreiber C, et al: Hypoplastic left heart syndrome with anomalous origin of the right coronary artery. Ann Thorac Surg 2006;81:341-343.

6. Ito $\mathrm{T}$, Niino M, Ishikawa J, et al: Hypoplastic left heart syndrome with a single coronary artery originating from the pulmonary artery. Acta Paediatr Jpn 1995;37:61-63.

7. DeRose JJ, Corda R, Dische MR, et al: Isolated left ventricular ischemia after the Norwood procedure. Ann Thorac Surg 2002;73:657-659.

8. Pizarro C, Davis DA, Galantowicz ME, et al: Stage I palliation for hypoplastic left heart syndrome in low birth weight neonates: Can we justify it? Eur J Cardiothorac Surg 2002;21:716-720.

9. Chaoui R, Tennsted C, Goldner B: Prenatal diagnosis of ventriculocoronary arterial fistula in a fetus with hypoplastic left heart syndrome and aortic atresia. $U l$ trasound Obstet Gynecol 2002;20:75-78.

10. Patel CR, Lane JR, Spector ML, et al: Prenatal diagnosis of ventriculocoronary arterial communication in fetuses with hypoplastic left heart syndrome. J Ultrasound Med 2006;25:245-249.

11. Bensky AS, Covitz W: Echocardiographic demonstration of a ventriculocoronary artery communication in a neonate with hypoplastic left heart syndrome. $J \mathrm{Am}$ Soc Echocardiogr 1994;7(3 Pt 1):324-326.

12. Freedom RM, Culham JA, Moes CA, et al: Selective aortic root angiography in the hypoplastic left heart syndrome. Eur J Cardiol 1976;4:25-29.

13. Beckman CB, Moller JH, Edwards JE: Alternate pathways to pulmonary venous flow in left-sided obstructive anomalies. Circulation 1975;52:509-516.

14. Baffa JM, Chen SL, Guttenberg ME, et al: Coronary artery abnormalities and right ventricular histology in hypoplastic left heart syndrome. J Am Coll Cardiol 1992;20:350-358.

15. Cheatham JP, Ruyle NA, McManus BM, et al: Origin of the right coronary artery from the descending thoracic aorta: Angiographic diagnosis and unique 


\section{CORONARY ANOMALIES IN LEFT HEART LESIONS}

coronary artery anatomy at autopsy. Cathet Cardiovasc Diagn 1987;13:321-324.

16. Bartram U, Grunenfelder J, Van Praagh R: Causes of death after the modified Norwood procedure: A study of 122 postmortem cases. Ann Thorac Surg 1997;64:1795-1802.

17. Vlodaver Z, Neufeld HN, Edwards JE: Pathology of coronary disease. Semin Roentgenol 1972;7:376394.

18. Muriago M, Sheppard MN, Ho SY, et al: Location of the coronary arterial orifices in the normal heart. Clin Anat 1997;10:297-302.

19. Ogden JA: Congenital anomalies of the coronary arteries. Am J Cardiol 1970;25:474-479.

20. Angelini P: Normal and anomalous coronary arteries: Definitions and classification. Am Heart $J$ $1989 ; 117: 418-434$

21. Roberts WC, Kragel AH: Anomalous origin of either the right or left main coronary artery from the aorta without coursing of the anomalistically arising artery between aorta and pulmonary trunk. Am J Cardiol 1988;62:1263-1267.

22. Menke DM, Waller BF, Pless JE: Hypoplastic coronary arteries and high takeoff position of the right coronary ostium. A fatal combination of congenital coronary artery anomalies in an amateur athlete. Chest 1985;88:299-301.

23. Mahowald JM, Blieden LC, Coe JI, et al: Ectopic origin of a coronary artery from the aorta. Sudden death in 3 of 23 patients. Chest 1986;89:668-672.

24. Lytrivi ID, Wong AH, Ko H, et al: Echocardiographic diagnosis of clinically silent congenital coronary artery anomalies. Int $J$ Cardiol 2007;doi:10.1016/j.ijcard.2007.04.063.

25. Frescura C, Basso C, Thiene G, et al: Anomalous origin of coronary arteries and risk of sudden death: A study based on an autopsy population of congenital heart disease. Hum Pathol 1998;29:689-695.

26. Vlodaver Z, Amplatz K, Burchell HB, et al: Coronary heart disease. Clinical, Angiographic and Pathologic Profiles. New York: Springer-Verlag, 1976, pp. 131133.

27. Piegger J, Kovacs P, Ambach E: Extremely high origin of the right coronary artery from the ascending aorta. Clin Anat 2001;14:369-372.

28. Gaudino M, Glieca F, Piergiorgio B, et al: Unusual right coronary artery anomaly with major implication during cardiac operations. Ann Thorac Surg 1997;64:838-839.

29. Ogino H, Miki S, Ueda Y, et al: High origin of the right coronary artery with congenital heart disease. Ann Thorac Surg 1999;67:558-559.

30. Thakur R, Dwivedi SK, Puri VK: Unusual "high take off" of the right coronary artery from the ascending aorta. Int $J$ Cardiol 1990;26:369-371.

31. King BD, Ambrose JA, Stein JH, et al: Anomalous origin of the right coronary artery from the ascending aorta above the left coronary sinus. Cathet Cardiovasc Diagn 1982;8:277-280.

32. Palomo AR, Schrager BR, Chahine RA: Anomalous origin of the right coronary artery from the ascending aorta high above the left posterior sinus of Valsalva of a bicuspid aortic valve. Am Heart J 1985;109:902-904.

33. Blake HA, Manion WC, Mattingly TW, et al: Coronary artery anomalies. Circulation 1964;30:927-940.

34. Nerantzis CE, Marianou SK: Ectopic "high" origin of both coronary arteries from the left aortic wall: Anatomic and postmortem angiographic findings. Clin Anat 2000;13:383-386.

35. Frommelt PC, Frommelt MA: Congenital coronary artery anomalies. Pediatr Clin N Am 2004;51:12731288 . 